\title{
Steady State Analysis of a Doubly Fed Induction Generator
}

\author{
Ahmad M. Alkandari ${ }^{1}$, Soliman Abd-Elhady Soliman ${ }^{2}$, Mansour H. Abdel-Rahman ${ }^{3}$ \\ ${ }^{1}$ College of Technological Studies, Department of Electrical Technology Sheweikh, Kuwait, Kuwait \\ ${ }^{2}$ Electrical Power and Machines Department, Misr University for \\ Science and Technology, Giza, Egypt \\ ${ }^{3}$ Department of Electrical Engineering, Mansoura University, Mansoura, Egypt \\ E-mail: \{kandari1, shadysoliman\}@yahoo.com
}

Received January 25, 2011; revised February 28, 2011; accepted March 16, 2011

\begin{abstract}
In this paper, we present the steady state analysis of a doubly-fed induction generator (DFIG) adopted for wind power generation. The three-phase induction machine connected to the network, to work as a generator for wind farms, is excited on the rotor circuit by a slip-frequency current injected to the rotor, from an exciter mounted on the same shaft of the machine. The resulting rotating magnetic field rotates at synchronous speed; as such the generated power has a constant frequency independent of the shaft speed. Effects of the excitation voltage magnitude and phase angle on the active and reactive power are studied, when the machine runs at constant speed. It has been shown that by controlling the excitation voltage magnitude and phase angle would control the mode of operation of the machine; motor mode or generator mode. Furthermore, the effects of the shaft speed on the active and reactive power at constant excitation voltage magnitude and constant phase angle are also investigated.
\end{abstract}

Keywords: Asynchronous Operation, Doubly Feed Induction Generator (DFIG), Wind Power

\section{Introduction}

The growing demand of energy in industrialized world and environmental problems determined some important decision at political level that consider even more important to improve the percentage of energy produced by renewable sources. It is well-known the Kyoto Protocol and other important regulations that take care of environmental problems. Also the European Parliament approved the document 2001/77/CE on the "promotion of electrical energy produced by renewable sources" attending that before 2020 the $22 \%$ of total consumed energy should be produced by renewable sources. In this frame a lot of efforts are devoted to increase the efficiency of the generation systems based on wind, sun, hydro and biomass.

Wind power seems to be one of the most interesting technologies, especially considering the developments in the last decade. The electrical energy generation by wind depends on different factors, in particular the wind speed and the characteristics of the wind turbine generator [1]. The unpredictability of the wind power, that is variable with time, determines fluctuating power outputs of wind energy conversion systems. This variable power genera- tion nature requires a careful analysis, design, and management of the generation system so that various approaches have been developed to study wind turbine generator behaviors.

There are different technical solutions that have been set up for different cases, for wind turbines in a range from less $1 \mathrm{~kW}$ to as large as $3 \mathrm{MW}$ or more, to obtain the maximum efficiency and reliability. Traditionally the wind power generation has used fixed-speed induction generators that represent a simple and robust solution, then variable speed turbines have been considered because they give higher energy, allow an extended control of both active and reactive power, and present less fluctuation in output power. The main solution adopted to realize wind generators can be divided, by electrical topology point of view and depending on the power, in the following categories [2]:

- Standard squirrel cage induction generator directly connected to the grid;

- Wound-rotor induction generator with variable rotor resistance;

- Doubly fed induction generator;

- Synchronous or induction generator with full-size power converter. 
Both induction and synchronous generators can be used for wind turbine systems. Induction generators can be used in a fixed-speed system or a variable-speed system, while synchronous generators are normally used in power electronic interfaced variable-speed systems. Mainly, three types of induction generators are used in wind power conversion systems: cage rotor, wound rotor with slip control by changing rotor resistance, and DFIG. The cage rotor induction machine can be directly connected into an ac system and operates at a fixed speed or uses a full-rated power electronic system to operate at variable speed. The wound rotor generator with rotorresistanceslip control is normally directly connected to an ac system, but the slip control provides the ability of changing the operation speed in a certain range. The DFIG provides a wide range of speed variation depending on the size of power electronic converter systems. In this chapter we first discuss the systems without power electronics except the thyristor soft starter, and then discuss the variable-speed wind turbine systems, including those with partially rated power electronics and the full-scale power electronic interfaced wind turbine systems.

In fixed-speed wind turbines, the generator is directly connected to the mains source grid. The frequency of the grid determines the rotational speed of the generator and thus of the rotor. The generator speed depends on the number of pole pairs and the frequency of the grid. The scheme consists of a squirrel-cage induction generator (SCIG), connected via a transformer to the grid. The wind turbine systems using cage rotor induction generators almost operate at a fixed speed (variation of $1 \%$ $2 \%$ ). The power can be limited aerodynamically by stall control, active stall control, or by pitch control. The advantage of wind turbines with induction generators is the simple and cheap construction. In addition, no synchronization device is required. These systems are attractive due to cost and reliability, but they are not fast enough (within a few ms) to control the active power. There are some other drawbacks also: the wind turbine has to operate at constant speed, it requires a stiff power grid to enable stable operation, and it may require a more expensive mechanical construction in order to absorb high mechanical stress since wind gusts may cause torque pulsations in the drive train and the gearbox. Other disadvantages with the induction generators are high starting currents and their demand for reactive power. They need a reactive power compensator to reduce (almost eliminate) the reactive power demand from the turbine generators to the grid. It is usually done by continuously switching capacitor banks following the production variation (5 - 25 steps) [2].

In variable-speed systems the generator is normally connected to the grid by a power electronic system. For synchronous generators and for induction generators without rotor windings, a full-rated power electronic system is connected between the stator of the generator and the grid, where the total power production must be fed through the power electronic system. For induction generators with rotor windings, the stator of the generator is connected to the grid directly. Only the rotor of the generator is connected through a power electronic system. This gives the advantage that only a part of the power production is fed through the power electronic converter. This means the nominal power of the converter system can be less than the nominal power of the wind turbine. In general the nominal power of the converter may be $30 \%$ of the power rating of the wind turbine, enabling a rotor speed variation in the range of $30 \%$ of the nominal speed. By controlling the active power of the converter, it is possible to vary the rotational speed of the generator and thus of the rotor of the wind turbines [2].

Doubly-fed induction machines can be operated as a generator as well as a motor in both sub-synchronous and super synchronous speeds, thus giving four possible operating modes. Only the two generating modes at subsynchronous and super-synchronous speeds are of interest for wind power generation.

In a DIFG the slip rings are making the electrical connection to the rotor. If the generator is running super-synchronously, electrical power is delivered to the grid through both the rotor and the stator. If the generator is running sub-synchronously, electrical power is delivered into the rotor from the grid. A speed variation of $\pm 30 \%$ around synchronous speed can be obtained by the use of a power converter of $30 \%$ of nominal power. Furthermore, it is possible to control both active $\left(P_{\text {ref }}\right)$ and reactive power $\left(Q_{\text {ref }}\right)$, which gives a better grid performance, and the power electronics enables the wind turbine to act as a more dynamic power source to the grid. The DFIG system does not need either a soft starter or a reactive power compensator. The system is naturally a little bit more expensive compared to the classical systems However, it is possible to save money on the safety margin of gear and reactive power compensation units, and it is also possible to capture more energy from the wind. [2]

In Reference [1] the case of variable speed dual-excited synchronous machine is investigated. For its control possibilities, this machine is particularly suitable for variable-speed constant frequency applications like wind power generation systems. The mathematical model of the wind turbine and the generator is presented a control technique for output power maximization is proposed. It has been demonstrated that using the proposed control algorithm it is possible to achieve a significant increment on the power generated in comparison with that obtained 
using an unregulated induction machine.

Reference [3] presents a dynamic model of an important contemporary wind turbine concept namely a doubly fed (wound rotor) induction generator with a voltage source converter feeding the rotor. This wind turbine concept is equipped with rotor speed, pitch angle and terminal voltage controllers. It was shown that it is possible to develop a set of equations describing the behavior of the wind turbine. Furthermore, controllers for the rotor speed, the pitch angle and the terminal voltage were developed. The behavior of the system was investigated using two measured wind sequences.

Reference [4] presents the modal analysis of a grid connected to a DFIG. The change in modal properties for different system parameters, operating points, and grid strengths are computed and observed. The results offer a better understanding of the DFIG intrinsic dynamics, which can also be useful for control design and model justification.

Vector control is already applied to the DFIG control, which makes the DFIG gain good performance in the wind energy capturing operation. But in the two traditional vector control schemes, the stator magnetizing current is considered invariant in order to simplify the rotor current inner-loop controller. The two schemes are capable of performing very well when the grid is in normal condition [5]. However, when the grid disturbance, such as grid voltage dip or swell fault, occurs, the control performance will be getting worse, the rotor over current will occur, which seriously reduce the ride-through ability of the DFIG wind energy generation system. Based on the accurate model of the DFIG, the deficiency of the traditional vector control is deeply investigated. The improved control schemes of the two typical traditional vector control schemes used in DFIG is proposed, and the simulation study of the proposed and traditional control schemes is carried out. The validity of the proposed modified schemes to control the rotor current and to improve the ride-through ability of the DFIG wind energy generation system is proved in Reference [6] by the comparison study.

The growing integration of wind energy into power networks will have a significant impact on power system stability. With the development of Wind Turbine (WT) techniques, the DFI becomes the dominant WT type used in wind farms [6]. In this situation, DFIG should be modeled properly in power system stability analysis. A detailed model of the WT with DFIG and its associated controllers is presented, based on which the small signal stability model is derived. Small signal stability analysis shows that the DFIG control can significantly improve the stability of WT system. Applying a set of optimized controller parameters, the stability can be further enhanced [7].

This paper presents the steady state analysis of DFIG, where we assume that the three phase induction machine is connected to work as a generator for wind turbine farms, the machine is excited in the rotor circuit by a slip frequency current comes from an exciter mounted on the same shaft, with the main generator, so that the speed of the resulting flux in the air gap is always synchronous speed independent of the wind speed. Effects of the excitation voltage as well as the excitation voltage angle on the total active and reactive power, when the machine runs at constant speed are studied in this paper. Furthermore, effects of the shaft speed on the active and reactive power at constant excitation voltage and phase angle are also studied.

\section{Steady State Analysis of DFIG}

In the steady state analysis we assume a three-phase slip-ring induction machine, where the rotor is excited from a slip frequency exciter mounted on the same shaft of the rotating machine, and the stator is connected to the power grid having a constant voltage and constant frequency. The excitation voltage is expressed in a phasor form as $V_{f} \angle \gamma$. If the core resistance is neglected, then the equivalent circuit in p.u is given in Figure 1.

The loop voltage equations in per unit are given by:

$$
\begin{gathered}
V=I_{s}\left(R_{1}+j X_{1}\right)+I_{r}\left(j X_{m}\right) \\
V_{f} \angle \gamma=I_{s}\left(j S X_{m}\right)+I_{r}\left(R_{2}+j S X_{1}\right)
\end{gathered}
$$

Solving Equations (1) and (2) yields

$$
I_{S}=\frac{\left(V R_{2}+V_{f} X_{m} \sin \gamma\right)+j\left(S V X_{r}-V_{f} X_{m} \cos \gamma\right)}{\left(R_{s} R_{r}-S X_{s} X_{r}+S X_{m}^{2}\right)+j\left(S R_{s} X_{r}+R_{r} X_{s}\right)}
$$

while the rotor current is given by Equation (4).

Let us define the parameters $a, b, c, d, e$ and $g$ as

$$
\begin{aligned}
& a=\left(V R_{r}+V_{f} X_{m} \sin \gamma\right) ; \\
& b=\left(S V X r-V_{f} X_{m} \cos \gamma\right) ; \\
& c=\left(R_{s} R_{r}-S X_{s} X_{r}+S X_{m}^{2}\right) ; \\
& d=\left(S R_{s} X_{r}+R_{r} X_{s}\right) \\
& e=\left(V_{f} R_{s} \cos \gamma-V_{f} X_{s} \sin \gamma\right) ; \\
& g=\left(V_{f} X_{s} \cos \gamma+R_{s} V_{f} \sin \gamma-S X_{m} V\right) .
\end{aligned}
$$

$$
I_{r}=\frac{\left(V_{f} R_{s} \cos \gamma-V_{f} X_{s} \sin \gamma\right)+j\left(V_{f} X_{s} \cos \gamma+R_{s} V_{f} \sin \gamma-S X_{m} V\right)}{\left(R_{s} R_{r}-S X_{s} X_{r}+S X_{m}^{2}\right)+j\left(S R_{s} X_{r}+R_{r} X_{s}\right)}
$$




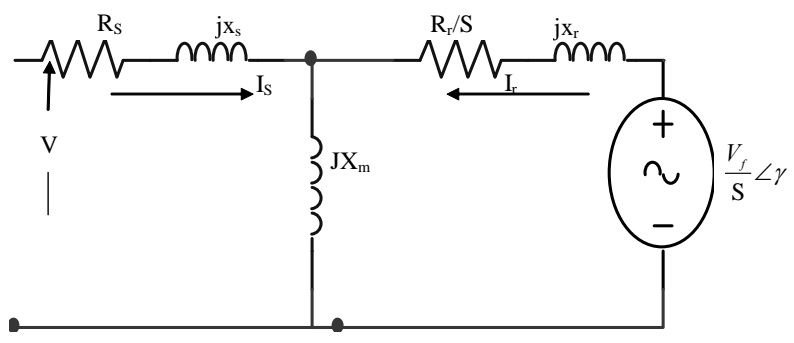

Figure 1. Steady state equivalent circuit of DFIG referred to the stator.

Then the stator and rotor currents can be written as:

$$
\begin{aligned}
& I_{s}=\frac{a+j b}{c+j d} \\
& I_{r}=\frac{e+j g}{c+j d}
\end{aligned}
$$

The active and reactive power of the stator can be obtained as:

$$
\begin{aligned}
S_{S} & =V I_{S}^{*}=P_{S}+J Q_{S} \\
P_{S} & =\operatorname{Real}\left[V I_{s}^{*}\right] \\
Q_{S} & =\operatorname{Im}\left[V I_{S}^{*}\right]
\end{aligned}
$$

Substituting for $I_{S}$ then the active and reactive power of the stator is given by:

$$
\begin{aligned}
& P_{S}=\frac{V(a c-a d)}{c^{2}+d^{2}} \\
& Q_{S}=\frac{-V(b c-a d)}{c^{2}+d^{2}}
\end{aligned}
$$

Note that the stator active power is positive for motoring operation and is negative for generating operation and vice versa for the reactive power.

The expressions for active and reactive power of the rotor (exciter) are given as:

$$
\begin{aligned}
S_{r} & =V_{f} \angle \gamma I_{r}^{*}=P_{r}+J Q_{r} \\
P_{r} & =\operatorname{Real}\left[V_{f} \angle \gamma I_{r}^{*}\right] \\
Q_{r} & =\operatorname{Im}\left[V_{f} \angle \gamma I_{r}^{*}\right]
\end{aligned}
$$

Substituting $I_{r}$ into (9) we obtain

$$
\begin{aligned}
P_{r} & =\frac{V_{f}(e c+g d) \cos \gamma+V_{f}(c g-e d) \sin \gamma}{c^{2}+d^{2}} \\
Q_{r} & =\frac{V_{f}(e c+g d) \sin \gamma-V_{f}(c g-e d) \cos \gamma}{c^{2}+d^{2}}
\end{aligned}
$$

Note that, if the excitation voltage $V_{f}$ equals zero, the machine performs in accordance with the basic operating characteristics similar to a conventional induction machine. Obviously, no power active or reactive is generated. Equation (10) describes the steady state operation of a doubly feed induction machine.

\section{Steady State Characteristics}

In studying the steady state characteristics we assume that the stator of the main machine is connected to an infinite bus source, and the primary circuit of the exciter is connected to the same source as such the output of the exciter is a source of a slip frequency and injects power to the slip rings of the rotor of the main machine. As such the current in the stator of the main machine has a constant frequency independent of the shaft speed.

\subsection{Effects of Excitation Voltage Magnitude}

In this study we assume a constant excitation voltage is applied to the machine rotor while the machine speed changes from zero to double the synchronous speed, i.e. $S$ varies from 1 to -1 . The parameters of the machine used in this study are given in Tables A.1 and A.2 [7].

Figure 2 gives the results obtained for the stator active power when the slip is changed from -1 to 1 , i.e. speed changes to double the synchronous speed, while we changed the excitation voltage magnitude from 0 to 0.6 p.u in step of 0.2 p.u. Examining these curves reveals the following:

- At $V_{f}=0$, induction motor operation, the machine delivers power to the network, via the stator windings, at speed greater synchronous speed, slip greater than -0.05 . This is obviously correct, since the machines runs as an induction generator

- At excitation voltage magnitude of 0.2 and 0.4 p.u the machine delivers power to the source at this speed ranges.

- For excitation voltage magnitude of 0.6 , the machine delivers power to the source at sub-synchronous speed, speed less than synchronous speed.

Figure 3 gives the results obtained for the stator reactive power versus the speed at a constant excitation voltage

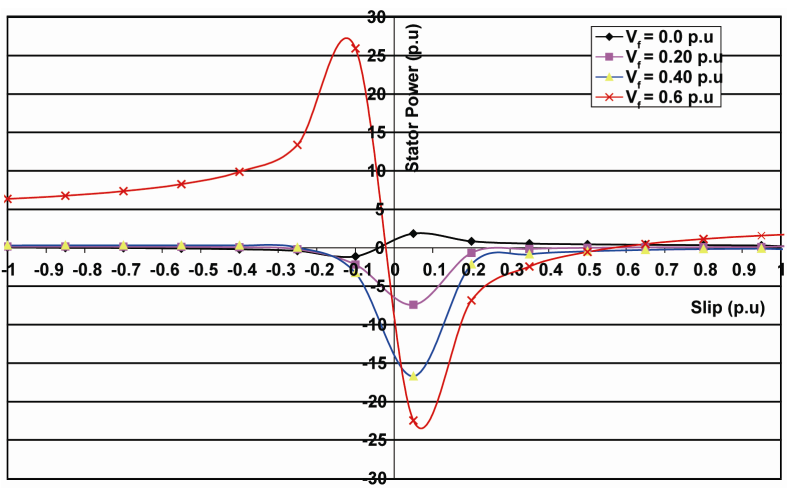

Figure 2. Stator active power versus speed at constant excitation voltage. 


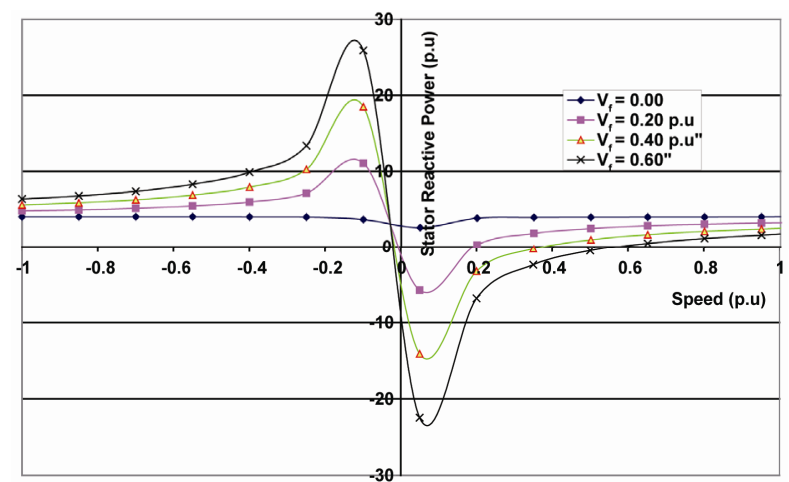

Figure 3. Stator reactive power versus the speed at constant excitation voltage.

magnitude ranging from $V_{f}=0.0$ p.u to $V_{f}=0.60$ p.u. Examining these curves reveals the following:

- At sub-synchronous the machine absorbs reactive power from the network, while at super-synchronous speed the machine delivers reactive power to the network.

- The maximum absorbed or delivered reactive power to the network occurs at the same speed.

- At the same speed, the reactive power increases as the excitation voltage increases.

Figure 4 depicts the active power of the rotor at different excitation voltage magnitude when the machine speed varies from zero to double the synchronous speed.

Examining this table reveals that:

- The rotor is absorbed active power from the source at all speeds regards the excitation voltage magnitude.

- The maximum power absorbed at different excitation voltage magnitudes occurs at the same speed.

- When the excitation voltage is zero, the rotor is short circuited, no power is absorbed by the rotor (induction motor operation).

Figure 5 shows the variation of the rotor reactive power at different excitation voltage magnitudes, when the speed varies from zero to double the synchronous speed. It can be noticed, from this figure, that:

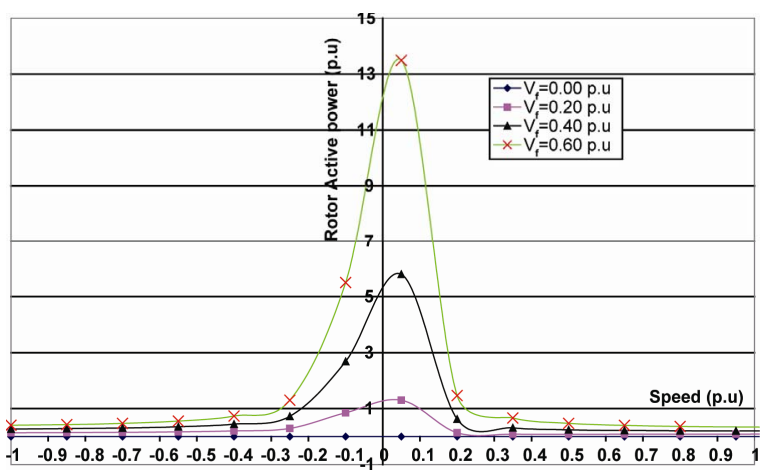

Figure 4. Rotor active power versus the speed at different excitation voltage.

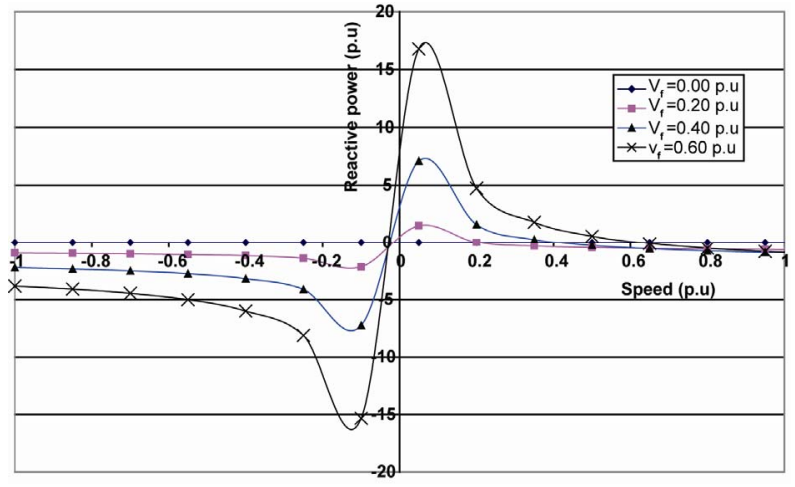

Figure 5. Rotor reactive power versus speed at different excitation voltage.

- At sub-synchronous speed the machine absorbs reactive power from the source, while at super-synchronous speed the machine delivers reactive power to the network, (asynchronous capacitor) at different excitation voltage magnitudes, and the maximum of these reactive powers occurs at the same speed.

\subsection{Effects of the Excitation Voltage Angle}

In this section the characteristics of the machine is studied, where we assume that the machine run at super-synchronous speeds and we change the excitation voltage angle, the angle between the excitation voltage and the source voltage, from $-90^{\circ}$ to $90^{\circ}$ while we kept excitation voltage magnitude constant at $V_{f}=0.2$ p.u. Figure 6 shows the results obtained for the stator active power. Examining this curve reveals that:

- At synchronous speed, $s=0.0$, the machine behaves as a synchronous machine, generator, and delivers power to the network, ( $P, \delta$, ) characteristics.

- At super-synchronous speed the machine delivers power to the network for positive excitation voltage angle and absorbs power from the network for negative excitation voltage angle.

- The maximum delivers powers occur at different excitation voltage angles.

Figure 7 gives the same characteristics but the machines runs above synchronous speed. Examining this curve reveals the following remarks:

- When the machine runs just speed $20 \%$ more than the synchronous speed, it delivers power to the network for the range of negative excitation voltage angle and little bit positive excitation voltage angle.

- The maximum delivered power occurs at different excitation voltage angle, negative angle, for every super-synchronous speed.

- The machine delivers power to the network at this rang of speeds, although the excitation voltage angle is zero. 


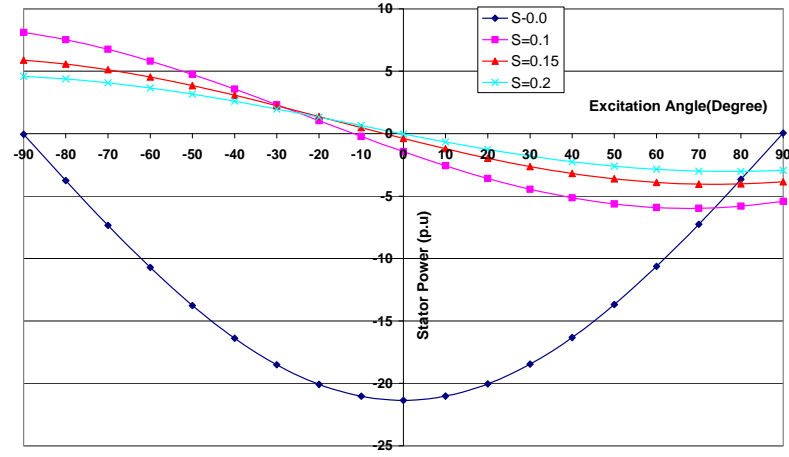

Figure 6. Stator power versus excitation angle at constant speed.

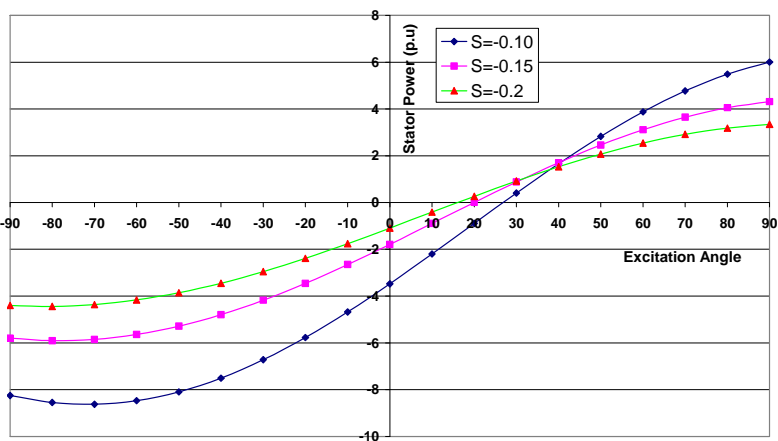

Figure 7. The stator power versus the excitation angle when the machine above synchronous speed, $V_{f}=0.2$ p.u.

Figures 8 and 9 give the excitation power for subsynchronous and super-synchronous speed operation, respectively, and the excitation voltage magnitude is kept constant at $V_{f}=0.2$ p.u

Examining these curves reveals the following conclusions:

- At synchronous speed, $S=0.0$, the excitation power is constant regardless the magnitude of the excitation voltage angle.

- The excitation power having the same trend regardless the speed of the machine, sup or super synchronous speed.

- The machine delivers power to the network at almost negative excitation voltage angle and at sub-synchronous and super-synchronous speed, respectively.

- The maximum positive or maximum negative powers occur at different excitation voltage angle.

Figures 10 and 11 give the stator reactive power variation with the excitation voltage angle, when the machine runs at sub-synchronous and super-synchronous speeds, respectively, while the excitation voltage magnitude is kept constant at $V_{f}=0.20$ p.u. Examining these figures reveals that :

1) At synchronous speed, $S=0.0$, the machine behaves as a non-salient pole synchronous machine and the

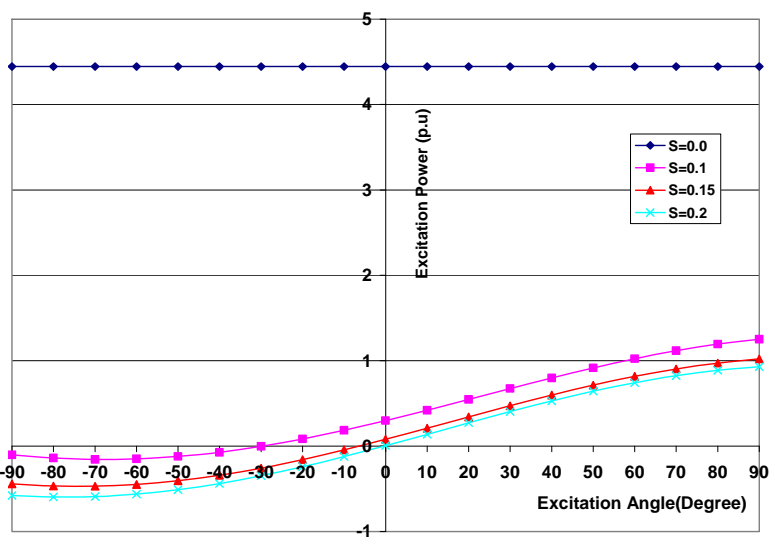

Figure 8. Excitation power versus excitation angle.

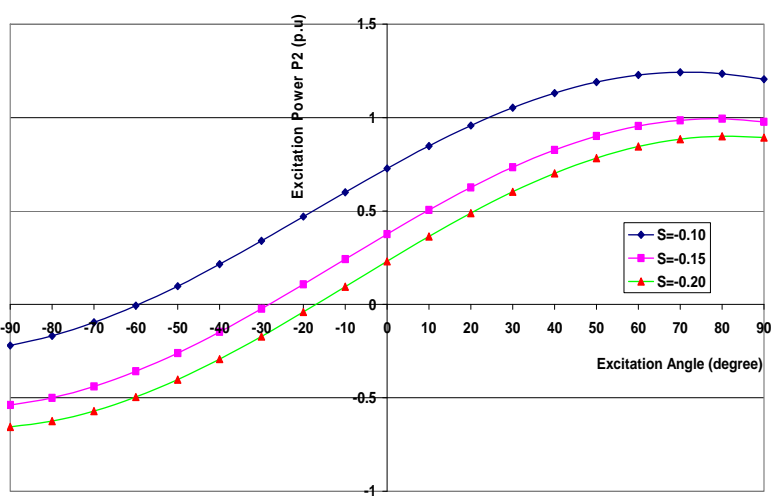

Figure 9. Excitation power versus excitation angle when the machine runs above synchronous speed, $V_{f}=0.2$ p.u.

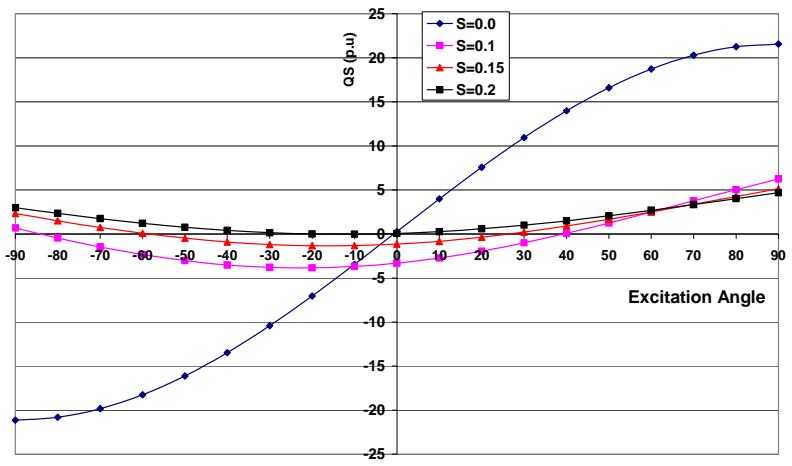

Figure 10. Stator reactive power versus excitation angle at $V_{f}=0.2$ p.u.

excitation voltage angle becomes the rotor angle, i.e. the power angle.

2) The machine absorbs and delivers reactive power to the network at different excitation voltage angle (Note that positive reactive power means absorption, inductive reactive power, while negative reactive power means delivering, capacitive reactive power).

3) The maximum stator reactive power either positive or negative occurs at the same excitation voltage angle 


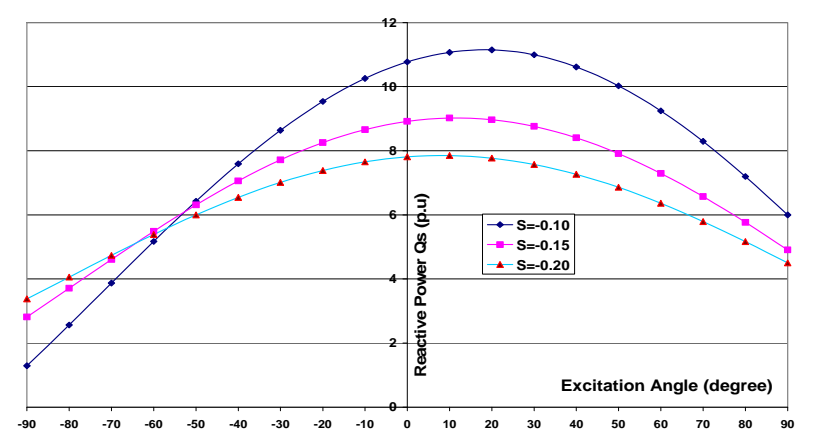

Figure 11. Stator reactive power when the machine runs above synchronous speed, $V_{f}=0.2$ p.u.

for every speed in the range.

Figure 12 shows the net active power delivered to the network versus the excitation voltage angle when the excitation voltage magnitude is kept constant, while the machine runs at super-synchronous speed. And the excitation voltage magnitude is kept constant at 0.2 p.u. Examining this figure reveals the following remarks:

- When the machine runs at synchronous speed it delivers more power to the network than the other speed.

- At super-synchronous speeds the machine delivers power to the network for positive excitation voltage angle and absorbs power for negative excitation voltage angles.

- At sup-synchronous speeds the machine delivers the maximum power at the same excitation voltage angle independent of the machine shaft speed.

Figure 13 depicts the variation of the total reactive power versus the excitation voltage angle, when the excitation voltage magnitude is kept constant at 0.2 p.u, while the machine runs at sup synchronous speed. It can be noticed from this figure that:

- When the machine runs at synchronous speed, the machine delivers reactive power to the source, when the excitation voltage angle varies from zero to $-90^{\circ}$, and absorbs the same magnitude of the reactive power when the excitation voltage angle varies from zero to $90^{\circ}$. i.e. the curve is inversely symmetrical at excitation voltage angle equals zero.

- At speeds rather than the synchronous speed, the machine absorbs and delivers reactive power to the network for different modes of excitation voltage angles.

- The maximum delivery of reactive power occurs at the same excitation voltage angle independent of the machine speed, except at synchronous speed.

\section{Conclusions}

In this paper the steady state analysis of DFIG is developed, we assume that the machine is excited on the rotor

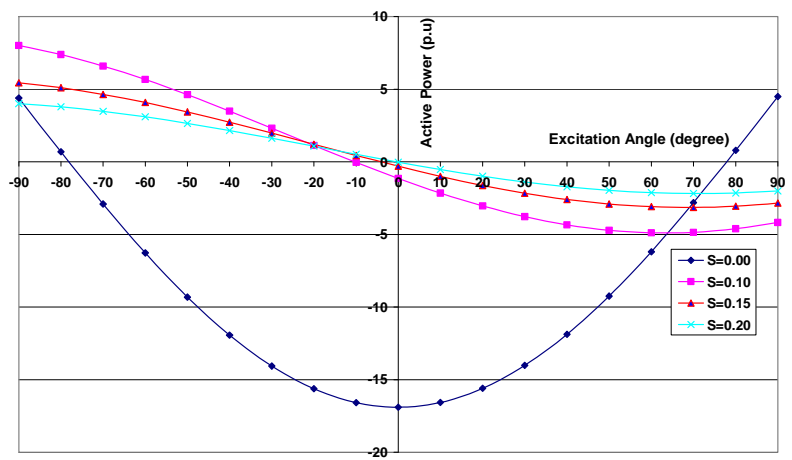

Figure 12. Tatol active power (p.u) versus excitation angle.

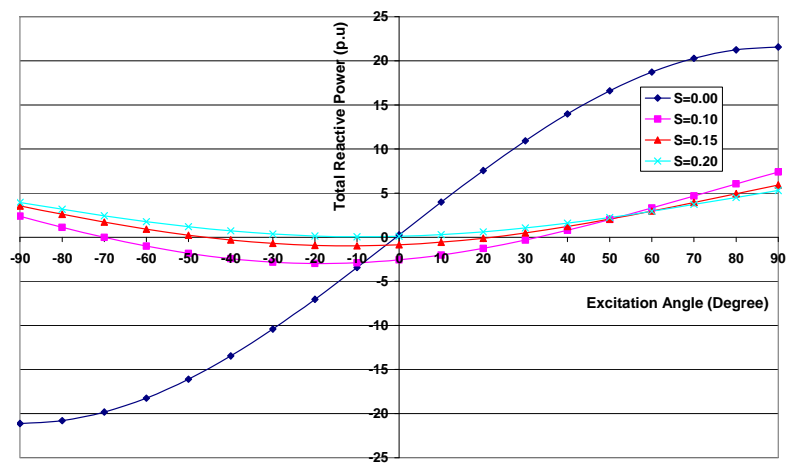

Figure 13. Tatol reactive power versus excitation angle.

side by a slip-frequency current injected from an exciter mounted on the same shaft of the machine. The resulting rotating magnetic field rotates at synchronous speed. Effects of the excitation voltage magnitude and angle on both the active and reactive power when the machine runs at constant speed are investigated. It has been shown that controlling the excitation voltage magnitude and phase angle controls the mode of operation of the machine; motor or generator mode. Furthermore, effects of the shaft speed on the active and reactive power at constant excitation voltage magnitude and constant phase angle are also investigated. It can be concluded that the power angle stability of conventional synchronous machine has no meaning in this type of generators. Studying the control of the machine terminal voltage is under study and the results will appear in a forthcoming paper.

\section{References}

[1] L. Piegari, R. Rizzo and P. Tricoli, "High Efficiency Wind Generators with Variable Speed Dual-Excited Synchronous Machines," International Conference on Clean Electrical Power 2007, Capri, 21-23 May 2007, pp. 795-800.

[2] F. Blaabjerg and Z. Chen, "Power Electronics for Modern Wind Turbine,” Morgan \& Claypool Publisher, San Rafael, 2006.

[3] J. G. Slootweg, H. Polinder and W. L. Kling, "Dynamic Modeling of a Wind Turbine with Doubly Fed Induction 
Generator," IEEE Power Engineering Society Summer Meeting, Vol. 1, 2001, pp. 644-649.

[4] F. Mei and B. Pal, "Modal Analysis of Grid-Connected Doubly Fed Induction Generators," IEEE Transactions on Energy Conversion, Vol. 22, No. 3, 2007, pp. 728-736. doi:10.1109/TEC.2006.881080

[5] Y. K. He, J. B. Hu and R. D. Zhao, "Modeling and Control of Wind-Turbine Used DFIG under Network Fault Conditions," Proceedings of the 8th International Conference on Electrical Machines and Systems, 2005, Nan-

\section{Nomenclature}

$I_{s}, I_{r}$ are the stator and rotor current, respectively.

$R_{s}$ and $R_{r}$ are the stator and rotor resistance, respectively.

$X_{s} \& X_{r}$ are the total stator and rotor reactance, respectively.

$$
\begin{aligned}
& X_{s}=x_{s}+X_{m} \\
& X_{r}=x_{r}+X_{m}
\end{aligned}
$$

$X_{m}=$ Magnetizing reactance

$x_{s} \& x_{r}$ are Leakage reactance of the stator and rotor respectively.

$S$ is the machine slip $=\frac{n_{s}-n}{n_{s}}, S$ is positive at sub-synchronous speed $n<n_{S}$ and negative at super-synchronous speed, $n>n_{S}$ respectively.

$V$ is the grid voltage having a constant frequency $f_{s}$.

$V_{f}$ is the excitation voltage magnitude, having constant frequency $f_{s}$.

$\gamma$ is the angle of the excitation voltage. jing, Vol. 2, 29 September 2005, pp. 986-991

[6] F. Wu, X.-P. Zhang, K. Godfrey and P. Ju, "Modeling and Control of Wind Turbine with Doubly Fed Induction Generator,” 2006 IEEE PES Power Systems Conference and Exposition, Atlanta, 29 October-1 November 2006.

[7] A. Petersson, "Analysis, Modeling and Control of Doubly-Fed Induction Generators for Wind Turbines” Ph.D. Thesis, Division of Electric Power Engineering, Department of Energy and Environment, Chalmers University of Technology, Goteborg, 2005.

\section{Appendix A.}

Table A.1. Parameters of the induction machines.

\begin{tabular}{lccc}
\hline Stator resistance & $R_{S}$ & $0.0022 \Omega$ & 0.010 p.u \\
\hline Stator leakage Reactance & $x_{S}$ & $0.1200 \mathrm{mH}$ & $0.180 \mathrm{p.u}$ \\
Rotor resistance & $R_{r}$ & $0.0018 \Omega$ & $0.009 \mathrm{p.u}$ \\
Rotor leakage Reactance & $x_{r}$ & $0.05 \mathrm{mH}$ & $0.070 \mathrm{p.u}$ \\
Magnetizing reactance & $X_{m}$ & $2.9 \mathrm{mH}$ & $4.400 \mathrm{p.u}$ \\
\hline
\end{tabular}

Table A.2. Base values.

\begin{tabular}{ccc}
\hline Base Voltage (Phase-neutral) & $V_{b}$ & $400 \mathrm{~V}$ \\
\hline Base Current & $I_{b}$ & $1900 \mathrm{~A}$ \\
Base Frequency & $\omega_{b}$ & $314 \mathrm{rad} / \mathrm{s}$ \\
Base Impedance & $Z_{b}=V_{b} / I_{b}$ & $0.21 \Omega$ \\
\hline
\end{tabular}

